\title{
Age differences in the quality of chronic pain: A preliminary study
}

\author{
Lucia Gagliese BSc, Ronald Melzack PhD
}

\author{
L Gagliese, $R$ Melzack. \\ Age differences in the quality of chronic pain: \\ A preliminary study. \\ Pain Res Manage 1997;2(3):157-162.
}

BACKGROUND: Recent studies of the relationship between age and the intensity of chronic pain report increases, decreases or no change in pain intensity as a function of age. These inconsistencies may be due in part to the pain assessment tools employed and their appropriateness with different age groups.

OBJECTIVES: To assess age differences in chronic pain by using several measures of pain intensity and a multidimensional measure of pain qualities in the same sample; to assess the consistency of pain intensity estimates obtained from different scales within age groups; to determine whether the failure rates for appropriately completing the scale (such as choosing more than one descriptor or making more than one mark on the Visual Analog Scale [VAS]) differ among age groups.

SUBJECTS: Seventy-nine adults aged 27 to 79 years with chronic arthritis pain.

MEASUREMENTS: The unidimensional pain intensity scales used were the VAS, the Verbal Descriptor Scale and the Behavioural Rating Scale. The multidimensional pain scale used was the short form McGill Pain Questionnaire (SF-MPQ). The Beck Depression Inventory was also administered.

RESULTS: Age-related decreases were found in the sensory and affective dimensions of chronic pain as measured with the SFMPQ. No age differences in pain intensity were measured with any of the unidimensional scales. These results were maintained after controlling for the effects of concurrent depressive symptomatology. Pain intensity estimates differed within groups, with verbal descriptors yielding the most consistent estimates in the elderly group. The elderly were significantly more likely to fail on the VAS than younger subjects. There were no age differences on any other measure.

CONCLUSIONS: There may be age-related changes in the quality but not in the intensity of chronic arthritis pain. Implications for clinical pain assessment in the elderly are discussed.

Key Words: Age Differences, Arthritis, Elderly, McGill Pain Questionnaire, Pain Assessment

\section{Différences d'âge et type de douleur chronique : étude préliminaire}

DONNÉES DE DÉPART : Selon de récentes études établissant un lien entre l'âge et l'intensité d'une douleur chronique, ce rapport fait état d'une augmentation, d'une diminution ou d'une absence de changement quant à l'intensité de la douleur en fonction de l'âge. Ces discordances peuvent être dues en partie aux outils de mesure de la douleur employés et à leur pertinence selon le groupe d'âge.

OBJECTIFS : Évaluer les différences de douleur liées à l'âge au moyen de plusieurs outils de mesure d'intensité de la douleur et d'une analyse multidimensionnelle des types de douleur au sein d'un même échantillon. Évaluer la cohérence des mesures d'intensité de la douleur obtenues au moyen de différentes échelles à l'intérieur d'un même groupe d'âge, déterminer si le taux d'échec au test d'évaluation (par exemple, choisir plus d'un descripteur ou poser plus d'une marque sur les échelles analogiques visuelles [ÉAV]) diffère d'un groupe à l'autre. SUJETS : Soixante-dix-neuf adultes âgés de 27 à 79 ans souffrant de douleurs arthritiques chroniques.

OUTILS DE MESURE : Les échelles unidimensionnelles d'intensité de la douleur utilisées ont été l'ÉAV, la Verbal Descriptor Scale et la Behavioural Rating Scale. L'échelle de mesure multidimensionnelle de la douleur a été la forme abrégée du Questionnaire McGill sur la douleur (SF-MPQ). Le Beck Depression Inventory a également utilisée.

RÉSULTATS : On a constaté une diminution liée à l'âge sur le plan des dimensions sensorielles et affectives de la douleur chronique mesurées au moyen du SF-MPQ. Aucune différence liée à l'âge quant à l'intensité de la douleur n'a été notée au moyen des échelles unidimensionnelles. Ces résultats se sont maintenus après que l'on ait contrôlé pour les effets d'une symptomatologie dépressive concomitante. Les évaluations d'intensité de la douleur ont différé à l'intérieur des groupes, les descripteurs verbaux ont donné lieu à des estimés plus constants dans le groupe âgé. Les gens âgés risquaient beaucoup plus d'échouer au test d'ÉAV que les sujets jeunes. On n'a noté aucune différence liée à l'âge pour les autres mesures.

CONCLUSIONS : Il pourrait y avoir des changements liés à l'âge quant à la qualité, mais non pas quant à l'intensité de la douleur de l'arthrite chronique. On présente ici les implications que cela pourrait avoir sur l'évaluation de la douleur clinique chez les gens âgés.

Department of Psychology, McGill University, Montreal, Quebec

Correspondence and reprints: Dr R Melzack, Department of Psychology, McGill University, 1205 Dr Penfield Avenue, Montreal, Quebec H3A 1 B1.

Telephone 514-398-6127, fax 514-398-4896, e-mail lucy@ego.psych.mcgill.ca

Received for publication May 28, 1997. Accepted July 23, 1997 
$T^{\prime}$ he evidence for age differences in the experience of chronic pain remains controversial. There have been reports suggesting that the intensity of chronic pain increases, decreases or does not change with age. We were able to locate 15 studies that measured age differences using standardized pain assessment scales. These tools can be divided into unidimensional, single-item measures of pain intensity and multidimensional measures of the experience or qualities of pain. It has been suggested that these two classes of pain assessment tools measure different components of the pain experience (1).

Ten studies have assessed age differences in the intensity of chronic pain using unidimensional scales. Six of these studies found no age differences in the intensity of chronic pain as measured with the Visual Analog Scale (VAS) (2-5) or the Multidimensional Pain Inventory (MPI) (6), which measures intensity on a seven-point numeric rating scale ranging from "no pain" to "very intense pain" $(7,8)$. There have also been reports that pain intensity, measured with the MPI (9) and VAS (10), decreases with age, yet other studies have found that elderly subjects report more intense pain than younger subjects on both the verbal descriptor scale (VDS) (11) and VAS (12). Despite these inconsistencies, the majority of the data suggest that pain intensity, as measured with unidimensional scales, may not be significantly related to age.

Comparisons among age groups using the McGill Pain Questionnaire (MPQ), a multidimensional measure of the sensory, affective, evaluative and miscellaneous components of pain (13), have also been inconsistent. Of the five studies using this measure, two found no age differences $(14,15)$, while three reported that advancing age was associated with lower MPQ scores $(8,16,17)$.

There may be many reasons for these inconsistencies, including the large cross-study variability in the age of the subjects and the type of pain experienced. In addition, the majority of the studies were conducted in pain clinics or specialized pain treatment facilities, where the elderly may be underrepresented and those who are seen may not be representative of the elderly population as a whole (18). As well, many of the studies included subjects with a variety of painful syndromes, which may have contributed to the inconsistent results.

In the present study, age differences in the intensity and experience of chronic pain were assessed with both unidimensional and

\begin{tabular}{|c|c|c|c|}
\hline & $\begin{array}{l}\text { Young } \\
(\mathrm{n}=19)\end{array}$ & $\begin{array}{l}\text { Middle-aged } \\
\quad(n=37)\end{array}$ & $\begin{array}{l}\text { Elderly } \\
(\mathbf{n}=23)\end{array}$ \\
\hline Age range (years) & $27-45$ & $46-59$ & $60-79$ \\
\hline Mean age \pm SD & $38.4 \pm 4.3$ & $51.3 \pm 3.5$ & $67.3 \pm 5.5$ \\
\hline$\%$ female & 68.4 & 90.8 & 65.2 \\
\hline \multicolumn{4}{|l|}{ Diagnosis: n (\%) } \\
\hline RA & $11(57.9)$ & $19(52.8)$ & $12(52.2)^{*}$ \\
\hline Osteoarthritis & $4(21.1)$ & $10(27.8)$ & $9(39.1)$ \\
\hline Other & $4(21.1)$ & $7(19.4)$ & $2(8.7)$ \\
\hline $\begin{array}{l}\text { Pain duration } \\
\quad \text { (years } \pm \text { SD) }\end{array}$ & $11.9 \pm 8.9$ & $13.7 \pm 14.8$ & $12.2 \pm 4.7^{*}$ \\
\hline $\begin{array}{l}\text { Number of joints } \\
\text { affected } \pm \text { SD }\end{array}$ & $7.7 \pm 4.3$ & $9.2 \pm 4.5$ & $6.0 \pm 3.9^{*}$ \\
\hline
\end{tabular}

multidimensional scales in the same sample. One other study included both types of measures. McCracken et al (8) found that increasing age was associated with lower scores on the sensory scale of the short form of the MPQ (SF-MPQ) (19) but was not related to scores on the VAS or numeric rating scale. However, the subjects in this study had a variety of painful disorders and were patients seen at a pain clinic. In the present study, subjects were recruited from the mailing lists of the Arthritis Society of Quebec and, thus, may be more representative of the chronic pain population than individuals seen in pain clinics. In addition, the pain assessment instruments were not completed as a part of any treatment program, removing any biases that might result from this condition. Furthermore, all the subjects in this study had pain due to an arthritic disorder, reducing the variability in pain reports that may result from pooling data from individuals with etiologically distinct pain syndromes.

\section{SUBJECTS AND METHODS}

\section{Subjects}

The subjects were adults with chronic arthritis pain who were randomly selected as potential participants from the membership rosters of the Arthritis Society of Quebec. One hundred fifty-two subjects were randomly chosen, and questionnaire packages were mailed to their homes. Eighty-two were returned, a response rate of $53.9 \%$. Three questionnaires were incomplete and were excluded from the study.

For purposes of analysis, the 79 subjects were divided into three age groups: young (19 subjects, 27 to 45 years old, average age $38.4 \pm 4.3$ years [mean $\pm \mathrm{SD}$ ); middle-aged ( 37 subjects, 46 to 59 years old, average age $51.3 \pm 3.5$ years); and elderly ( 23 subjects, 60 to 79 years old, average age $67.3 \pm 5.5$ years). The majority of the subjects reported that they had received a diagnosis of rheumatoid arthritis; the remainder reported diagnoses of either osteoarthritis or another rheumatological disorder such as fibromyalgia or degenerative disc disease. The proportion of subjects reporting each of these diagnoses was not significantly different among the three groups $\left(\chi^{2}=2.56\right.$, $\mathrm{P} \leq 0.63$ ). In addition, the duration of pain and the number of joints affected were not significantly different among the three age groups. Table 1 presents demographic information on each of the groups.

\section{Procedure}

Questionnaires, a cover letter explaining the project and two consent forms were mailed to each subject. The cover letter instructed subjects to complete the questionnaire and mail it with one copy of the signed consent form to the experimenters in the self-addressed, stamped envelope that was included with the materials.

\section{Materials}

Each subject completed a comprehensive questionnaire, which has been described previously (20). For the present analysis only the following measures will be considered.

Multidimensional pain measure: The SF-MPQ (19) is a multidimensional measure of the quality of pain experienced. It is made up of 15 adjectives, drawn from the full length MPQ. Subjects indicate the extent, from none to severe, to which they experience each quality of pain. This scale gives Pain Rating Index total (PRI-T), sensory (PRI-S) and affective (PRI-A) scores. Helme et al (21) suggested that the SF-MPQ is appropriate for use with elderly patients. 
TABLE 2

Pain scale failure rates by age group

\begin{tabular}{lcccc}
\hline Pain scale & Young & Middle-aged & Elderly \\
\hline $\begin{array}{l}\text { Short form McGill Pain } \\
\quad \text { Questionnaire: \% (n) }\end{array}$ & $5.3(1)$ & $0(0)$ & $13.0(3)$ \\
Visual Analog Scale: \% (n) & $0(0)$ & $18.9(7)$ & $30.4(7)^{*}$ \\
Verbal Descriptor Scale: \% (n) & $0(0)$ & $5.4(2)$ & $13.0(3)$ \\
Behavioural Rating Scale: \% (n) & $0(0)$ & $0(0)$ & $8.7(2)$ \\
\hline${ }^{*} \chi^{2}=6.67, P \leq 0.05$. All other results were not significant. n Number of \\
subjects
\end{tabular}

\section{TABLE 3}

Correlation matrix of age, pain scales and depression scores

\begin{tabular}{l|cccccc}
\hline \multicolumn{1}{c}{} & Age & PRI-S & PRI-A & VAS & VDS & BRS-6 \\
\cline { 2 - 7 } Age & 1.00 & - & - & - & - & - \\
PRI-S & -0.32 & 1.00 & - & - & - & - \\
PRI-A & -0.28 & $0.65^{* *}$ & 1.00 & - & - & - \\
VAS & 0.09 & 0.29 & 0.40 & 1.00 & - & - \\
VDS & -0.09 & 0.34 & 0.38 & $0.46^{* *}$ & 1.00 & - \\
BRS-6 & 0.07 & 0.20 & 0.25 & $0.46^{* *}$ & $0.41^{*}$ & 1.00 \\
BDI & -0.02 & 0.08 & 0.27 & 0.36 & 0.19 & 0.27 \\
\hline
\end{tabular}

*P $\leq 0.001 ; * * P \leq 0.0001$. BDI Beck Depression Inventory; BRS-6 Behavioural Rating Scale; PRI Pain Rating Index -A-Affective, -S-Sensory, -T-Total; VAS Visual Analog Scale; VDS Verbal Descriptor Scale

\section{TABLE 4}

Unidimensional pain scale scores \pm SD by age group

\begin{tabular}{lccc}
\hline & Young & Middle-aged & Elderly \\
\hline Visual Analog Scale & $52.26 \pm 24.6$ & $66.63 \pm 22.3$ & $62.4 \pm 27.1$ \\
Verbal Descriptor Scale & $2.84 \pm 0.9$ & $3.06 \pm 1.2$ & $2.45 \pm 0.9$ \\
Behavioural Rating Scale & $2.26 \pm 0.7$ & $2.57 \pm 1.1$ & $2.29 \pm 0.8$ \\
\hline All results not significant & & & \\
\end{tabular}

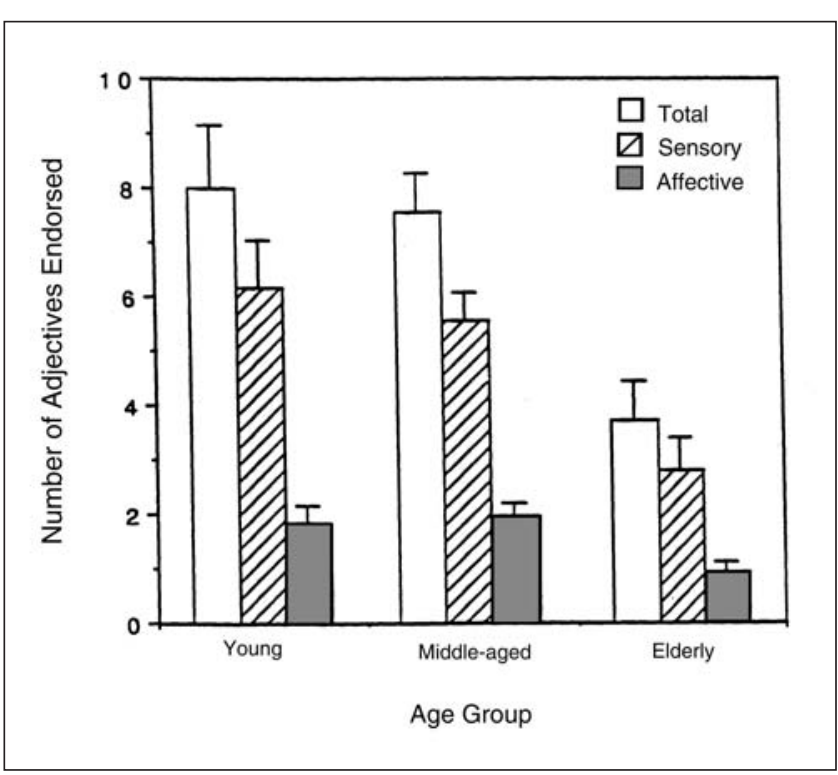

Figure 1) Short form McGill Pain Questionnaire total, sensory and affective scores by age group. Total $(P \leq 0.004)$, sensory $(P \leq 0.005)$ and affective $(\mathrm{P} \leq 0.02)$ scores were significantly lower in the elderly groups than in the younger groups

\section{Failure rates}

\section{RESULTS}

unidimensional intensity measure and is made up of a $100 \mathrm{~mm}$-long line anchored with descriptors of the extremes of pain intensity such as "no pain" and "worst pain possible" (22). Subjects indicate which point along the line best represents their current pain. There is strong evidence for the validity and reliability of this scale when used with younger subjects (see 23 for a review). Preliminary data indicate that the failure rate on this scale does not differ among age groups (24). The VDS measures pain intensity by using a list of six adjectives or descriptors ranging from "no pain" to "excruciating" (13). Subjects choose the descriptor that best describes their pain. Preliminary data suggest that this scale may be appropriate for use with the elderly (24) and that scores obtained by elderly pain subjects on the VDS and VAS are significantly correlated $(21,24)$. The Behavioural Rating Scale (BRS-6) (25) measures pain intensity in terms of its behavioural effects. Subjects choose the best description of their pain out of six options ranging from "no pain" to "pain present, cannot be ignored, rest or bedrest required." This scale has shown adequate reliability and validity. There is also evidence that age is not associated with accuracy of responding on this scale (26).

Depression measure: The Beck Depression Inventory (BDI) (27) is a 21-item self-report assessment of various symptoms of depression. The scale is widely used and has demonstrated adequate reliability and validity when used with different age groups (28).
The number of subjects per age group who failed to complete each pain questionnaire is presented in Table 2. These failures consisted of leaving the question blank, choosing more than one option, or making circles or circling the anchors on the VAS. There was some incorrect responding on each scale. A series of $\chi^{2}$ tests revealed that the failure rate was significantly different among the age groups on the VAS, with the elderly significantly more likely to respond incorrectly on this scale than the younger groups $\left(\chi^{2}=6.67, \mathrm{P} \leq 0.05\right)$. There were no significant differences among age groups on the SFMPQ, VDS or BRS-6.

Pain scale correlations: Table 3 presents the correlations among each of the pain scales, age and the BDI. Due to the large number of correlations calculated, a more conservative significance level was required to minimize the possibility of type I error. A Bonferroni correction determined that $\mathrm{P} \leq 0.001$ was required for statistical significance. Using this criterion, the three unidimensional measures were significantly correlated with each other. The subscales of the SF-MPQ were also significantly correlated. However, none of the unidimensional measures was significantly correlated with either subscale of the SF-MPQ. Furthermore, none of the pain measures was significantly correlated with age or BDI scores. 


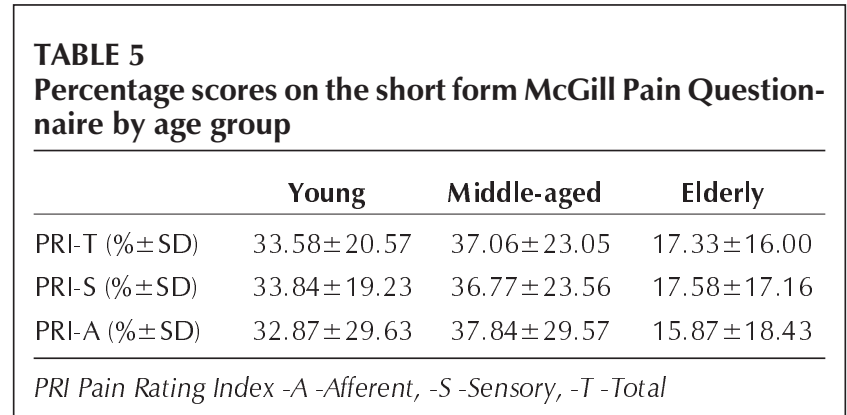

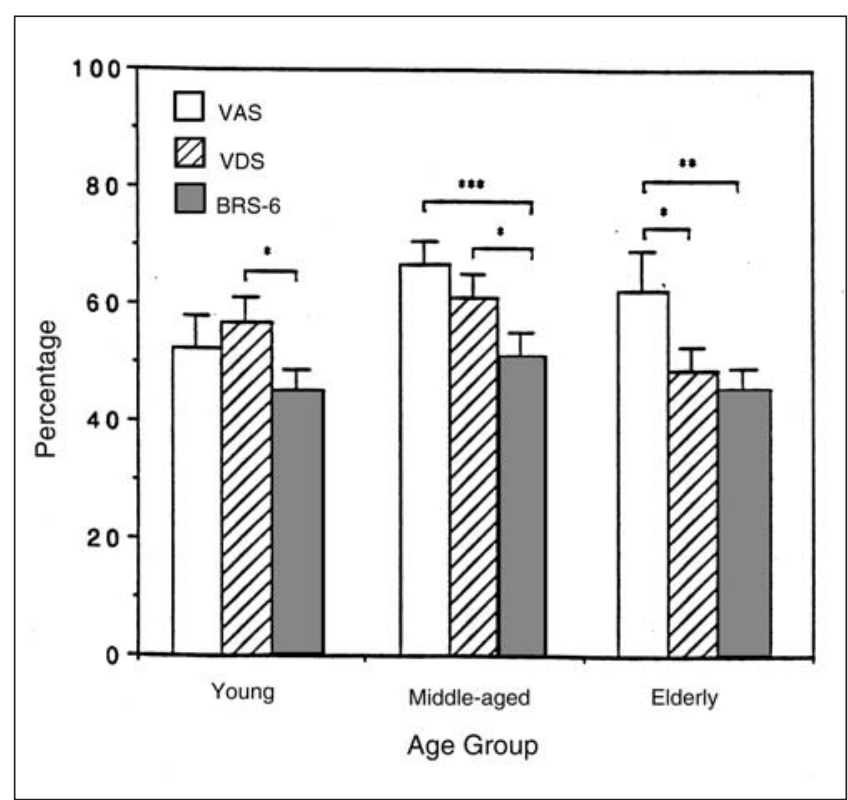

Figure 2) Pain intensity scores (percentage) by age group. There was no significant age effect $(\mathrm{P} \leq 0.12)$ but a significant effect of scale. ${ }^{*} \mathrm{P} \leq 0.05$; **P $\leq 0.005 ; * * * \mathrm{P} \leq 0.001$. BRS-6 Behavioural Rating Scale; VAS Visual Analog Scale; VDS Verbal Descriptor Scale

Age differences in pain measures: To assess whether there were any age differences in the intensity of chronic pain, a MANOVA with age group as the independent factor and BRS-6, VAS and VDS as the dependent factors was conducted. There was no effect of age group on any of the unidimensional scales (Table 4). Another MANOVA with the PRI-T, PRI-S and PRI-A as dependent factors and age group as the independent factor was conducted to assess age differences in the experience of chronic pain. Significant differences among the age groups were found on the SF-MPQ (PRI-T $\mathrm{F}[2,72]=6.02, \mathrm{P} \leq 0.004$; PRI-S $\mathrm{F}[2,72]=5.63, \mathrm{P} \leq 0.005$; PRI-A $\mathrm{F}[2,72]=4.01, \mathrm{P} \leq 0.02)$. The above analyses were repeated using BDI scores as a covariate to control for the effect of depression levels on pain intensity and SF-MPQ scores. There were no changes in the pattern of significant results.

Post hoc means comparisons of the SF-MPQ scores revealed that the elderly group had significantly lower scores than the middle-aged and young groups on both the PRI-T and PRI-S. The elderly group had significantly lower scores than the middle-aged but not the young group on the PRI-A. The young and middle-aged groups did not differ on any of the SF-MPQ scores (Figure 1).

Consistency of pain intensity estimates: To compare the pain intensity reported on each scale, scores were converted to percentages

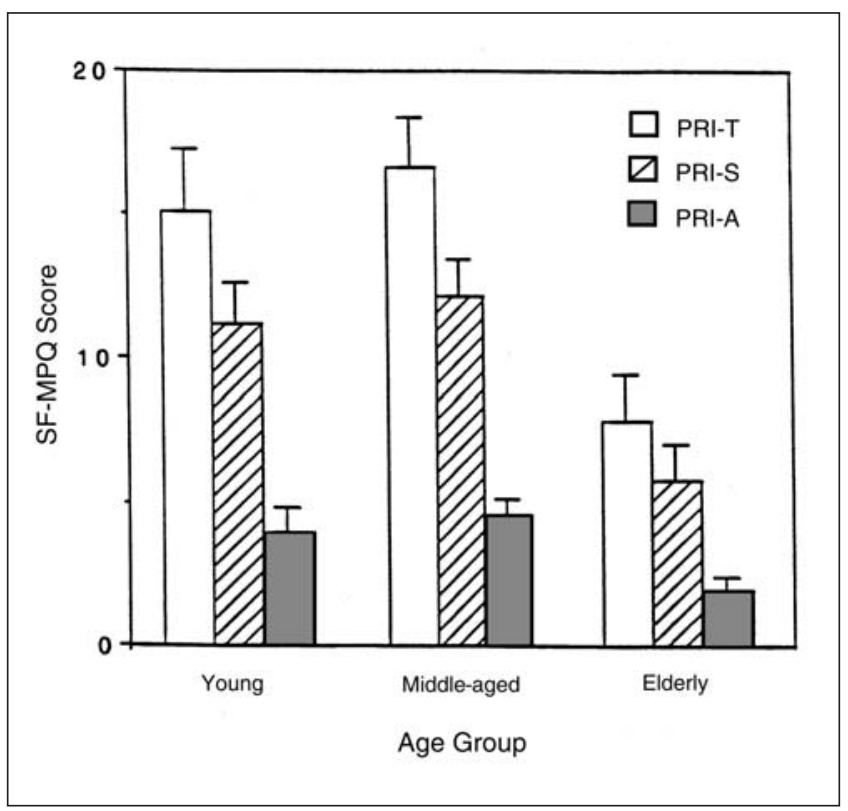

Figure 3) Number of adjectives endorsed on the short form McGill Pain Questionnaire (SF-MPQ) by age group. The three groups were significantly different on both the sensory $(\mathrm{P} \leq 0.003)$ and affective $(\mathrm{P} \leq 0.01)$ Scales of the SF-MPQ. PRI Pain Rating Index -A -Afferent, -S -Sensory, $-\mathrm{T}$-Total

by dividing each subject's score by the maximum possible score for the scale and multiplying by 100 . The scores were converted to percentages rather than standard scores to allow for cross-scale and age-group comparisons. A Bartlett test for the homogeneity of variance across pain scales and age groups was not significant $\left(\chi^{2}=14.70, P \leq 0.20\right)$, further supporting the use of percentage scores.

ANOVA with age group as the between factor and pain scale percentage scores as the repeated measure was conducted to determine whether there were significant differences in the mean pain intensity as measured with the VAS, BRS-6 and VDS. The lack of any age effect on the measures of pain intensity was replicated $(\mathrm{P} \leq 0.12)$. There was no significant scale by age group interaction $(\mathrm{P} \leq 0.24)$. There was a significant effect of scale $(\mathrm{F}[2,118]=11.78, \mathrm{P} \leq 0.0001)$. Pairwise comparisons of the scales indicated that the BRS-6 was significantly different from the VDS in the young group $(\mathrm{P} \leq 0.04)$ and from both the VDS $(\mathrm{P} \leq 0.03)$ and VAS $(\mathrm{P} \leq 0.001)$ in the middleaged group. The VDS and VAS were not significantly different in either the young or middle-aged groups. In the elderly group, the VAS was significantly different from both the VDS $(\mathrm{P} \leq 0.04)$ and BRS-6 ( $\mathrm{P} \leq 0.005)$, which did not differ (Figure 2).

Detailed analysis of the SF-MPQ: A similar analysis was conducted with the percentage scores from the two subscales of the SFMPQ. There was a remarkable between-scale consistency in the severity of both the sensory and affective dimensions of pain in each age group, as well as a replication of the age differences reported above (Table 5).

To test whether the number of adjectives endorsed differed among the three groups, a MANOVA with the number of sensory and affective descriptors endorsed as the dependent variables and age group as the independent variable was conducted. There was a significant effect on both scales (PRI-S F[2,73]=6.44, P $\leq 0.003$; PRI-A F[2,73] $=4.95, \mathrm{P} \leq 0.01$ ). Post hoc comparisons revealed that 
the elderly group endorsed significantly fewer sensory words than either the young $(\mathrm{P} \leq 0.005)$ or middle-aged $(\mathrm{P} \leq 0.008)$ groups, who did not differ from each other. On the affective subscale, the elderly endorsed significantly fewer descriptors than the middle-aged group ( $\mathrm{P} \leq 0.009)$ but not the young group. The young and middleaged groups did not differ (Figure 3 ).

Figure 4 presents the proportion of subjects in each age group who endorsed each adjective on the SF-MPQ. The four most frequently chosen words were the same in each group: tiring, tender, aching and hot-burning. However, the proportion of subjects in each age group who chose the word was consistently lower in the elderly group than in the two younger groups. These differences were tested by $\chi^{2}$ analysis and were significant for the following sensory adjectives: shooting $\left(\chi^{2}=7.72, \mathrm{P} \leq 0.05\right)$, sharp $\left(\chi^{2}=6.56\right.$, $\mathrm{P} \leq 0.05)$, cramping $\left(\chi^{2}=11.05, \mathrm{P} \leq 0.005\right)$ and heavy $\left(\chi^{2}=5.96\right.$, $\mathrm{P} \leq 0.05)$; and the following affective adjectives: tender $\left(\chi^{2}=6.84\right.$, $\mathrm{P} \leq 0.05)$, tiring $\left(\chi^{2}=8.68, \mathrm{P} \leq 0.005\right)$ and fearful $\left(\chi^{2}=6.56, \mathrm{P} \leq 0.05\right)$.

\section{DISCUSSION}

The results of the present study, although preliminary, show that there are age-related decreases in the sensory and affective dimensions of chronic arthritis pain as measured with a multidimensional tool such as the SF-MPQ, even though there are no age differences in pain intensity measured with unidimensional scales. The evidence for this conclusion is compelling because both types of scales were used in the same subjects, all of whom had pain of similar origin and comparable duration. These results were maintained after controlling for the possible effects of concurrent depressive symptomatology. A similar pattern of age differences has been suggested by previous investigators (8) and may, in part, explain some of the inconsistencies among earlier studies.

There may be several reasons for the dissociation between pain scales observed in this study. First, age differences on the SF-MPQ may reflect age differences in response style. For instance, the elderly may be more reluctant than younger individuals to endorse the 'most intense' words on the MPQ (29) or the highest severity level on the SF-MPQ. However, it may be assumed that this would also cause the elderly to endorse lower levels of pain on the intensity measures, which the data show is not the case. A second possibility is that the elderly may simply fail to comprehend the demands of either or both types of pain assessment tools (30). The data regarding failure rates on the pain scales is instructive here. Consistent with Jensen et al (26), we found that increasing age was associated with higher failure rates on the VAS. In fact, the VAS was the only scale to show this pattern, suggesting that there may be something unique about it - perhaps the demand for abstract reasoning (31), which may be difficult for the elderly. The lack of age differences in the failure rate on the remaining scales suggests that the dissociation among the measures is not an artefact of the elderly's inability to comprehend the scales. A third explanation of the pattern of results is that the adjectives included in the SF-MPQ may not adequately describe the pain experienced by elderly individuals. There may be other words of equal or greater intensity that would capture the experience of pain in this group more accurately and, thus, eliminate the age differences. However, the most frequently chosen words were the same in all three age groups and are consistent with previous reports of the words used to describe arthritis pain $(10,32,33)$.

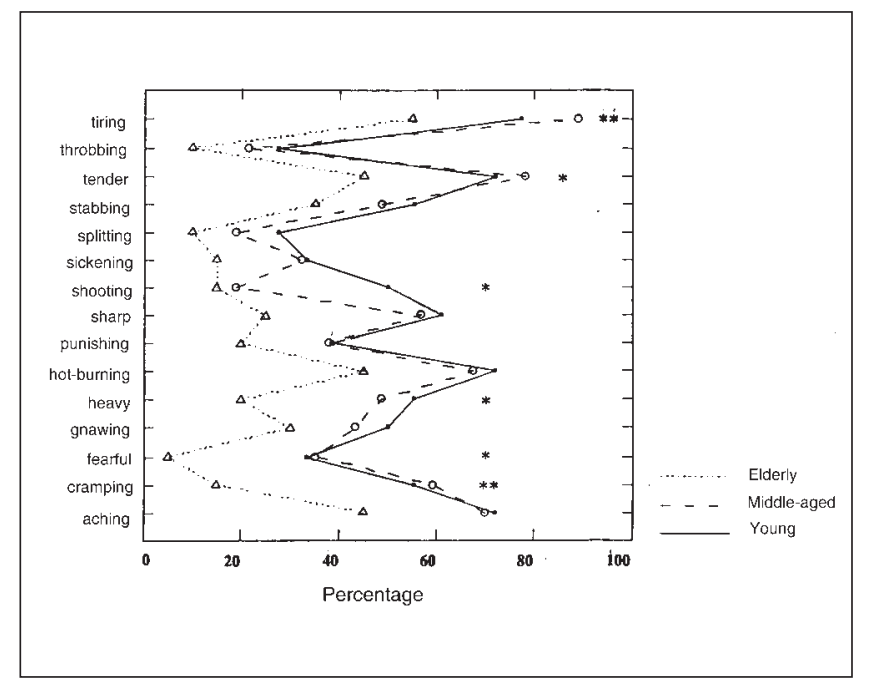

Figure 4) Proportion of subjects in each age group who endorsed each adjective on the short form McGill Pain Questionnaire. ${ }^{*} \mathrm{P} \leq 0.05$; **P $\leq 0.005$

This suggests that the present sample is representative of the larger population of individuals with chronic arthritis pain and that this type of pain is most commonly described as tiring, tender, aching and hot-burning.

The lower proportion of elderly subjects who chose the descriptors suggests that age differences and/or cohort effects in verbal fluency or the use of pain language may be responsible for the pattern of results. If such differences exist, the elderly may not conceptualize or rank the adjectives in the same ways as younger subjects or those in the original MPQ validation studies (13). This suggests that the discriminative capabilities of the MPQ may be age-related. These possibilities should be tested using the full-scale MPQ and in different chronic pain disorders.

Until such data are available, the most straightforward explanation for the results is that there may be age-related changes in the perceived quality of chronic pain rather than in pain intensity per se. In other words, the pain experienced by the elderly may be of comparable intensity to that of younger individuals, but its qualitative characteristics may differ. This is supported by the pattern of correlations. The lack of a significant correlation between the SF-MPQ and any of the unidimensional scales implies that these tools are measuring different components of pain.

Final conclusions regarding the interpretation of the dissociation must await future replication with the standard version of the MPQ and in samples with other painful disorders, although a similar pattern has been reported in postoperative pain levels (reviewed in 34). In addition, more data regarding the validity and reliability of these measures in the geriatric population are urgently needed.

The present data have important implications for the use of these scales. Specifically, the VAS may be inappropriate for use with elderly patients due to high failure rates and possible overestimation of pain intensity. The differences in the interscale intensity suggest that verbal descriptors may be the most valid and reliable type of unidimensional tool for this population. These conclusions are consistent with those of Herr and Mobily (24), who compared several different measures of pain intensity in a sample of elderly patients with leg pain. Although scores on all of the intensity scales used in this study 
were highly correlated, the mean scores were significantly different. This difference was due mostly to the VAS. Interestingly, the VDS was considered the easiest to complete and the best descriptor of pain in this sample.

The results of the present study also suggest that the SF-MPQ may be appropriate for use with the elderly. There was no age difference in failure rates on this scale, and among those who did complete the scale, there were high subscale consistency and correlation. The elderly chose fewer words and reported less pain, nonetheless, the same words were chosen with the greatest frequency by all three groups suggesting that the scale was being used in the same way by the subjects.

There are, however, several limitations to these conclusions. The sample was small, especially because those who failed to complete the pain scales were excluded from the analyses. Moreover, all subjects completed the scales in the same order, which may have in-

\section{REFERENCES}

1. Melzack R, Katz J. The McGill Pain Questionnaire: Appraisal and current status. In: Turk DC, Melzack R, eds. Handbook of Pain Assessment. New York: Guilford Press, 1992:152-68.

2. Harkins SW. Pain in the elderly. In: Dubner R, Gebhart FG, Bond MR, eds. Proceedings of the 5th World Congress on Pain. Amsterdam: Elsevier Science Publisher BV (Biomedical Division), 1988:355-7.

3. Middaugh SJ, Levin RB, Kee WG, Barchiesi FD, Roberts JM. Chronic pain: Its treatment in geriatric and younger patients. Arch Phys Med Rehabil 1988;69:1021-5.

4. Benbow SJ, Cossins L, Bowsher D. A comparison of young and elderly patients attending a regional pain centre. Pain Clin 1995;8:323-32.

5. Harkins SW, Lagua BT, Price DD, Small RE. Geriatric pain. In: Roy R, ed. Chronic Pain in Old Age. Toronto: University of Toronto Press Inc, 1995:127-59.

6. Kerns R, Turk D, Rudy D. The West Haven-Yale Multidimensional Pain Inventory (WHYMPI). Pain 1985;23:345-56.

7. Sorkin BA, Rudy TE, Hanlon RB, Turk DC, Steig RL. Chronic pain in old and young patients: differences appear less important than similarities. J Gerontol Psychol Sci 1990;45:P64-8.

8. McCracken LM, Mosley TH, Plaud JJ, Gross RT, Penzien DB. Age, chronic pain and impairment: Results from two clinical samples. VIIth World Congress on Pain. Paris, 1993.

9. Turk DC, Okifuji A, Scharff L. Chronic pain and depression: role of perceived impact and perceived control in different age cohorts. Pain 1995;61:93-101.

10. Parker J, Frank R, Beck NS, et al. Pain in rheumatoid arthritis: Relationship to demographic, medical, and psychological factors. J Rheumatol 1988;15:433-7.

11. Puder RS. Age analysis of cognitive-behavioral group therapy for chronic pain outpatients. Psychol Aging 1988;3:204-7.

12. Wilkieson CA, Madhok R, Hunter JA, Capell HA. Toleration, side-effects and efficacy of sulphasalazine in rheumatoid arthritis patients of different ages. Q J Med 1993;86:501-5.

13. Melzack R. The McGill Pain Questionnaire: Major properties and scoring methods. Pain 1975;1:277-99.

14. Lichtenberg PA, Swensen CH, Skehan MW. Further investigation of the role of personality, lifestyle and arthritic severity in predicting pain. J Psychosom Res 1986;30:327-37.

15. Corran TM, Helme RD, Gibson SJ. Comparison of chronic pain experience in young and elderly patients. VIIth World Congress on Pain. Paris, 1993.

16. Lichtenberg PA, Skehan MW, Swensen CH. The role of personality, troduced a sequence or fatigue effect. The order of completion was BRS-6, SF-MPQ, VAS and VDS. In addition, the generalizability of these results to the larger pain clinic population may be limited by the low response rate and the fact that only individuals with chronic arthritis pain were included in the present sample. Clearly, these results need to be replicated with random order of scale completion by using a larger sample with a variety of painful disorders and the full-scale MPQ to enable a richer assessment of age differences in the use of pain descriptors.

ACKNOWLEDGEMENTS: This work was supported by a Medical Research Council of Canada Studentship Grant to Lucia Gagliese and Grant A7891 from the Natural Sciences and Engineering Research Council of Canada to Ronald Melzack. We thank the staff and members of the Quebec Arthritis Society for their cooperation and Professor Rhonda Amsel for assistance with data analysis.

recent life stress and arthritic severity in predicting pain. J Psychosom Res 1984;28:231-6.

17. Benbow SJ, Cossins L, Wiles JR. A comparative study of disability, depression and pain severity in young and elderly chronic pain patients. VIIIth World Congress on Pain. Vancouver, 1996.

18. Harkins SW, Price DD. Assessment of pain in the elderly. In: Turk DC, Melzack R, eds. Handbook of Pain Assessment. New York: Guilford Press, 1992:315-31.

19. Melzack R. The short-form McGill Pain Questionnaire. Pain 1987;30:191-7.

20. Gagliese L, Melzack R. Lack of evidence for age differences in pain beliefs. Pain Res Manage 1997;2:19-28.

21. Helme RD, Katz B, Gibson S, Corran T. Can psychometric tools be used to analyse pain in a geriatric population? Clin Exp Neurol 1989;26:113-7.

22. Huskisson EC. Measurement of pain. Lancet 1974;ii:1127-31.

23. Jensen MP, Karoly P. Self-report scales and procedures for assessing pain in adults. In: Turk DC, Melzack R, eds. Handbook of Pain Assessment. New York: Guilford Press, 1992:135-51.

24. Herr KA, Mobily PR. Comparison of selected pain assessment tools for use with the elderly. Appl Nurs Res 1993;6:39-46.

25. Linton SJ, Gotestam KG. A clinical comparison of two pain scales: correlation, remembering chronic pain, and a measure of compliance. Pain 1983; 17:57-65.

26. Jensen MP, Karoly P, Braver S. The measurement of clinical pain intensity: A comparison of six methods. Pain 1986;27:117-26.

27. Beck AT. Depression Inventory. Philadelphia: Center for Cognitive Therapy, 1978.

28. Gallagher D. The Beck depression inventory and older adults: Review of its development and utility. Clin Gerontol 1986;5:149-63.

29. Oberle K, Paul P, Wry J, Grace M. Pain, anxiety and analgesics: A comparative study of elderly and younger surgical patients. Can J Aging 1990;9:13-22.

30. Herr KA, Mobily PR. Complexities of pain assessment in the elderly: Clinical considerations. J Gerontol Nurs 1991;17:12-9.

31. Kremer E, Atkinson JH, Ignelzi RJ. Measurement of pain: Patient preference does not confound pain measurement. Pain 1981;10:241-9.

32. Burckhardt CS. The use of the McGill Pain Questionnaire in assessing arthritis pain. Pain 1984;19:305-14.

33. Charter RA, Nehemkis AM, Keenan MA, Person D, Prete PE. The nature of arthritis pain. Br J Rheumatol 1985;24:53-60.

34. Gagliese L, Melzack R. The assessment of pain in the elderly. In: Lomranz J, Mostofsky DI, eds. Handbook of Pain and Aging. New York: Plenum Publishing. (In press) 


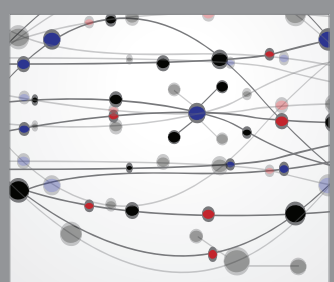

The Scientific World Journal
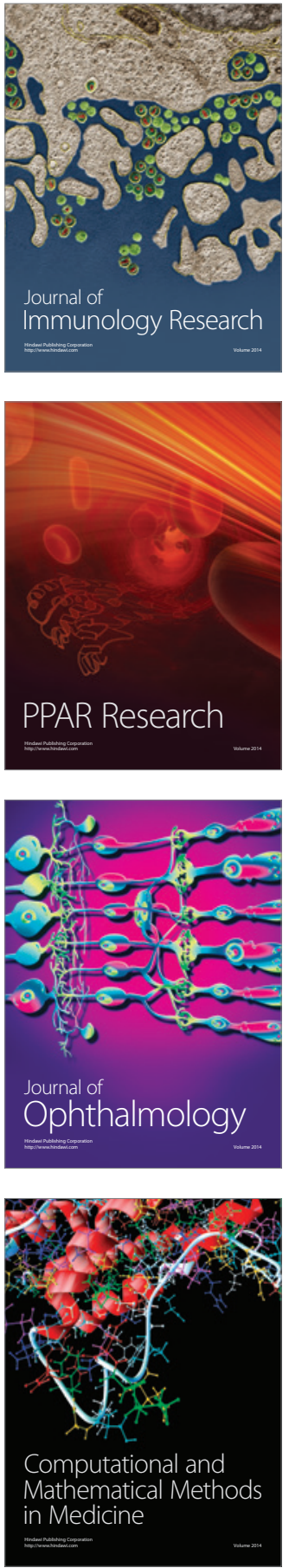

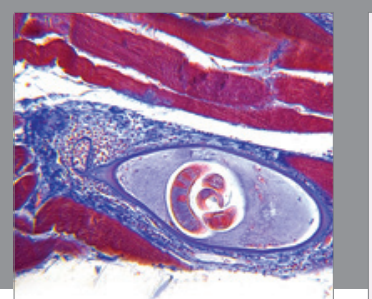

Gastroenterology Research and Practice

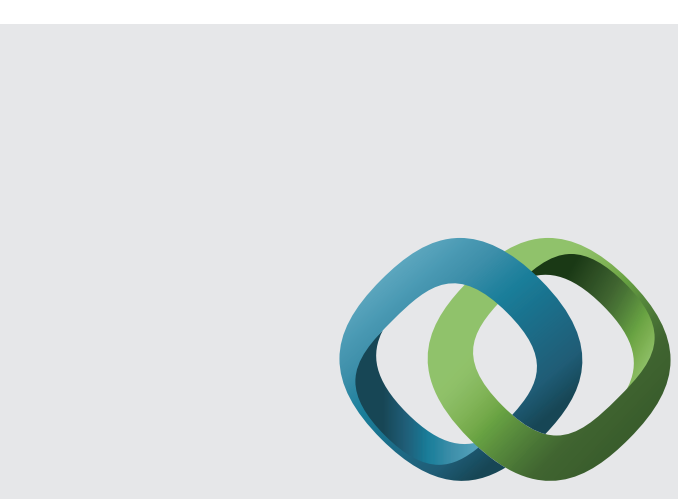

\section{Hindawi}

Submit your manuscripts at

http://www.hindawi.com
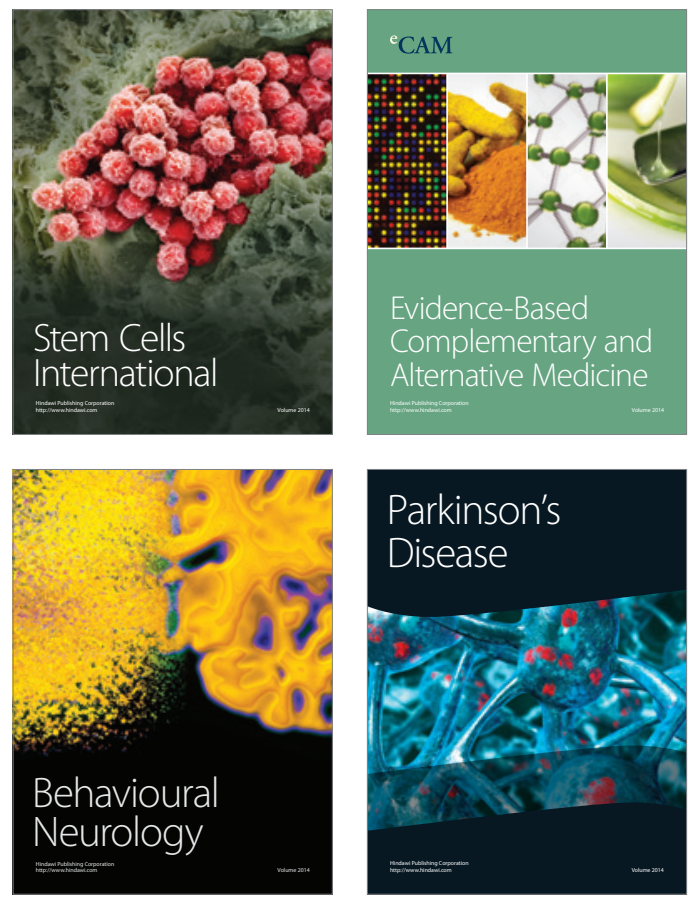
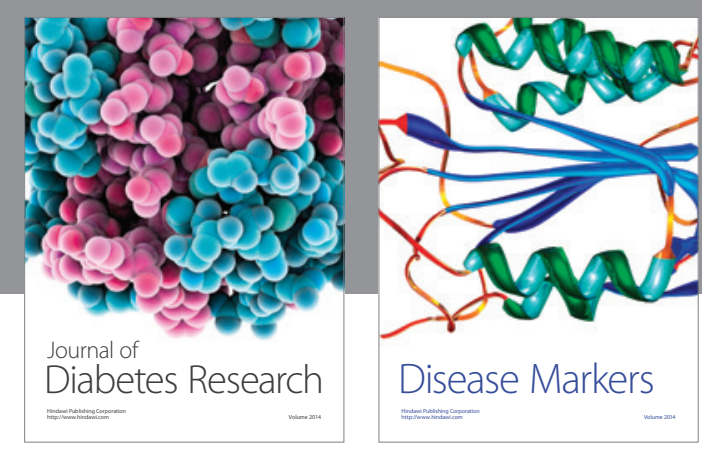

Disease Markers
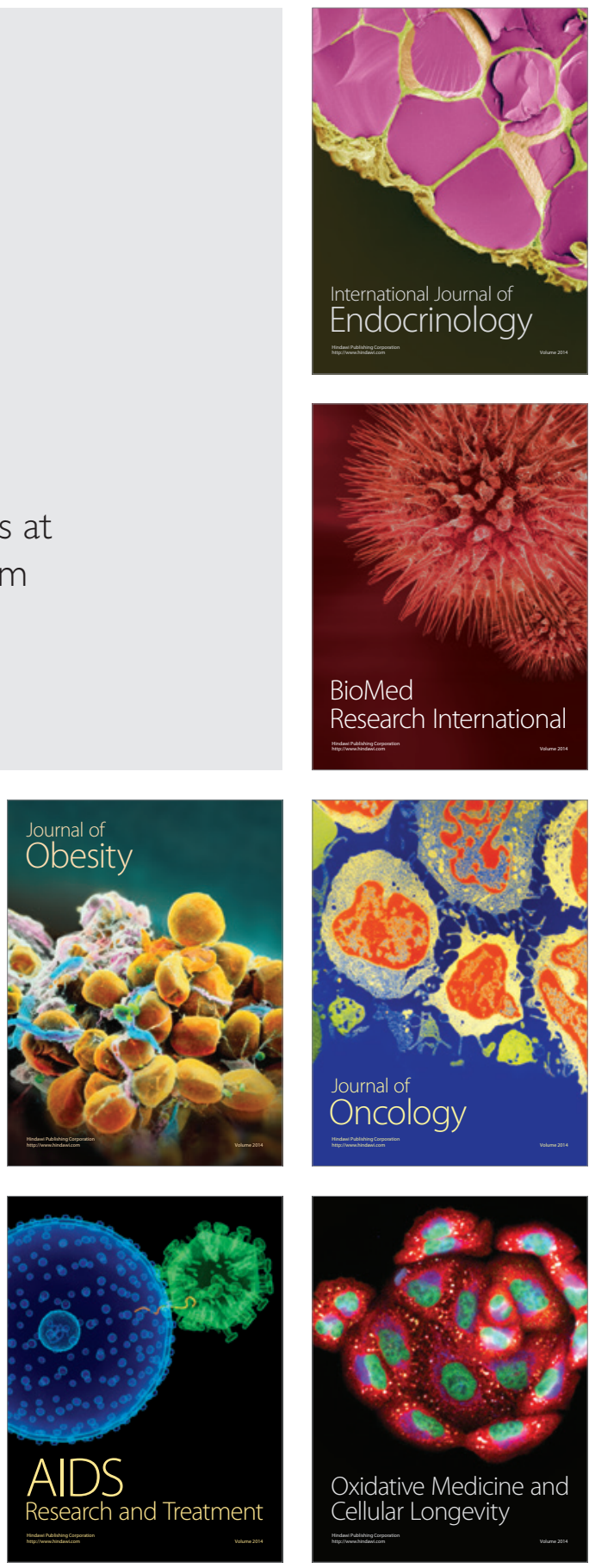